\title{
Adverse birth outcomes and its associated factors among women who delivered in North Wollo zone, northeast Ethiopia: a facility based cross-sectional study
}

\author{
Eskeziaw Abebe Kassahun ${ }^{1 *}$, Habtamu Dessie Mitku² and Mikiyas Amare Getu ${ }^{3}$
}

\begin{abstract}
Objective: Pregnancy is a happy time for women and their families although it can also a period of concern and anxiety, for some women, lose their babies during early or late pregnancy, give birth earlier than the expected date or face low birth weight. Therefore, this study aimed to assess the prevalence of adverse birth outcomes and associated factors among women who delivered in the North Wollo zone, northeast Ethiopia.

Result: The prevalence of adverse birth outcomes among women who delivered in North Wollo zone was 31. 8\%. Living in rural area $(A O R=1.8 ; 95 \% \mathrm{Cl} 1.13,2.78)$, age $\geq 34$ years $(A O R=2.2 ; 95 \% \mathrm{Cl} 1.21,4.05)$, mid-upper-arm circumference $<23 \mathrm{~cm}(\mathrm{AOR}=3.1 ; 95 \% \mathrm{Cl} 1.90,4.94)$, multigravida women $(\mathrm{AOR}=1.8 ; 95 \% \mathrm{Cl} 1.08,3.06)$, lack of antenatal care visit $(A O R=2.1 ; 95 \% \mathrm{Cl} 1.02,4.40)$ and complications during pregnancy $(A O R=2.1 ; 95 \% \mathrm{Cl} 1.23,3.55)$ were significantly associated with adverse birth outcomes. The prevalence of adverse birth outcomes was high and is a major public health problem in Ethiopia particularly in the study area. Hence, increasing the access to health institutions, developing strategies to prevent and treat complications, and providing focused antenatal care follow-up for pregnant women is recommended.
\end{abstract}

Keywords: Adverse birth outcomes, Preterm birth, Stillbirth, Low birth weight, North Wollo zone, Ethiopia

\section{Introduction}

Pregnancy is usually a happy time for most women and their families although it can also be a period of concern and anxiety, for some women lose their babies during early or late pregnancy and delivery earlier than the expected date or face low birth weight [1].

Adverse birth outcomes are common health problems in developing countries [2] and incur significant health consequences on infants, and emotional and economic costs on families, and communities across the world, particularly in resource-limited settings where health systems and access to and utilization of health services are weak [3-5].

\footnotetext{
*Correspondence: eskeziaw02@gmail.com

${ }^{1}$ Department of Midwifery, Faculty of Health Sciences, Woldia University, Woldia, Ethiopia

Full list of author information is available at the end of the article
}

Globally, preterm birth is the leading cause of neonatal deaths which is contributing to $35 \%$ of the world's neonatal mortality. It's also the leading cause of disability and ill health later in life. Out of 7.6 million deaths of underfive children, $17 \%$ are due to prematurity [6]. Each year, 15 million babies are preterm birth and more than one million dies [7]. As a result, many of the survivors face physical and neurological problems and, the onset of communicable and non-communicable diseases or educational disabilities $[7,8]$ for life. More than $60 \%$ of the preterm births take place in South Asia and Sub-Saharan Africa [7]. According to the Ethiopian profile of preterm and low-birth weight prevention and care report, 320,000 babies are born in each year of which 24,400 die at the age of less than 5 years due to direct complications of preterm birth [9].

Low-birth-weight babies experience growth retardation and inhibited cognitive developments, besides, to 
severe health problems from immediately after birth to later life $[10,11]$.

Globally, more than 20 million infants $(15.5 \%$ of all births) are born with low birth weight, $95.6 \%$ of them in developing countries. Around 15\% of low-birth-weight occurs in Sub-Saharan Africa [12]. According to the 2016 Ethiopian Demographic and Health Survey (EDHS) report, $13 \%$ of infants weighed less than $2.5 \mathrm{~kg}$ at birth [13].

Worldwide, over 2.6 million deliveries are stillbirths $98 \%$ of which occur in low and middle-income countries. About $60 \%$ of the stillbirths are in rural areas, and more than half occur among conflict and emergency zones $[14,15]$.

Although the Ethiopian government has developed strategy and plan to improve the wellbeing of mothers and children [16], the level of adverse birth outcomes are a major public health problem in areas such as Shire, Tigray, (22.6\%) [17], Gondar (23\%) [18], and Hosanna, (24.5\%) [19]. Consequently, the mortality rate of neonates, infants, and under five-children has been 29,48 , and 67 per 1000 live births, respectively [13]. Therefore, this study aimed to assess the prevalence of adverse birth outcomes and associated factors among women who delivered in the health institutions of North Wollo.

\section{Main text \\ Methods \\ Study design and settings}

An institution based cross-sectional study was conducted on 462 delivered mothers from March 2017 to June 2018. North Wollo zone is found $521 \mathrm{~km}$ from Addis Ababa, the capital of Ethiopia. It has 65 health centers and 3 hospitals. According to the 2017 Zonal Health Administrative Office report, 65 health centers gave delivery services to 600 women, while the three hospitals served 60 women per week. About 24\% of the women were of childbearing age.

\section{Sample size and sampling procedures}

All women who delivered in North Wollo zone health institutions were included in the study. However, women who gave birth with unknown last normal menstrual period (LNMP) or who had no a reliable ultrasonography results and severely ill were excluded. The required sample size was calculated using the single population proportion formula by considering the proportion of adverse birth outcomes as $22.7 \%$ taken from a previous study in Gondar [20], a 95\% confidence interval (CI), 4\% margin of error (d) and $10 \%$ non-response rate; the final sample was 462 women. First, the health institutions were stratified into hospitals and health centers. Then, by the random sampling method and rule of thumb (20\%), thirteen health centers and one hospital were selected. Finally, using the systematic random sampling method and proportional allocation to each selected health institution, 462 women were selected and interviewed.

\section{Measurement}

Adverse birth outcomes A baby is said to be preterm, if born before 37 completed weeks of gestation but after 28 weeks of gestation or low birth weight, if its birth weight is below $2500 \mathrm{~g}$ and stillbirth, if the infant died in the womb or during intrapartum period after 28 weeks of gestation [21]. If a woman met at least one of the above conditions, it is considered as an adverse birth outcome.

\section{Data collection tools and techniques}

Data was collected through pretested and structured interviewer-administered questionnaire. It was first prepared in English and translated to Amharic (the local language), and back-translated to English again. A total of 28 data collectors (BSc. in Midwifery) were involved in the data collection process. The purposes and objectives of the study were clearly explained to participants before data collection.

\section{Data quality controls}

The questionnaire was pretested on 24 women in Kobo primary hospital out of the study area. Twenty-eight data collectors were selected from the selected health institutions. Interviewers received a total of 15 days of intensive training before data collection. During data collection, any personal identifiers were not recorded.

\section{Data processing and analysis}

After the data collection, data was entered in EpiData 3.10 and exported to SPSS version 20 for analysis. Both bivariable and multivariable logistic regression analysis were carried out to identify factors associated with adverse birth outcomes. In bivariate logistic regression analysis, variables with p-value less than $20 \%$ were considered into the multivariable analysis to control the possible effect of confounders. Adjusted odds ratio (AOR) with a 95\% confidence interval (CI) was calculated to see the strength and significant association. Variables having a p-value less than 0.05 in the multivariable logistic regression analysis were considered as statistically significant.

\section{Results}

\section{Sociodemographic and economic characteristics}

A total of 462 women were interviewed, which makes a response rate of $100 \%$. The majority $(76.8 \%)$ of the women were in the age range of 20-34 years. About 61.9 and $93.5 \%$ of women lived in urban areas and married, respectively. Moreover, $26.4 \%$ of women were illiterate and $38.7 \%$ were farmers (Table 1 ). 
Table 1 Sociodemographic, medical and behavioral characteristics of respondents in North Wollo zone, northeast Ethiopia, $2017(n=462)$

\begin{tabular}{|c|c|c|}
\hline Variables & Frequency & Percentage \\
\hline \multicolumn{3}{|l|}{ Religion } \\
\hline Orthodox Christian & 385 & 83.3 \\
\hline Protestant & 3 & 0.6 \\
\hline Muslim & 74 & 16.1 \\
\hline \multicolumn{3}{|l|}{ Age (years) } \\
\hline$<20$ & 39 & 8.4 \\
\hline $20-34$ & 355 & 76.8 \\
\hline$>34$ & 68 & 14.7 \\
\hline \multicolumn{3}{|l|}{ Family size } \\
\hline$\leq 5$ & 403 & 87.2 \\
\hline$>5$ & 59 & 12.8 \\
\hline \multicolumn{3}{|l|}{ Marital status } \\
\hline Married & 432 & 93.5 \\
\hline Unmarried & 30 & 6.5 \\
\hline \multicolumn{3}{|l|}{ Women's education } \\
\hline Unable to read and write & 122 & 26.4 \\
\hline Able to read and write & 81 & 17.5 \\
\hline Primary (1-8th) school & 87 & 18.8 \\
\hline Secondary (9-12th) school & 72 & 15.6 \\
\hline College or higher education & 100 & 21.6 \\
\hline \multicolumn{3}{|l|}{ Partner's occupation } \\
\hline Governmental employee & 129 & 27.9 \\
\hline Merchant & 96 & 20.8 \\
\hline Farmer & 179 & 38.7 \\
\hline Private employer & 34 & 7.4 \\
\hline Others $^{\mathrm{a}}$ & 24 & 5.2 \\
\hline \multicolumn{3}{|c|}{ Time to reach nearby health institution (min) } \\
\hline$\leq 30$ & 223 & 48.3 \\
\hline$>30$ & 239 & 57.7 \\
\hline \multicolumn{3}{|l|}{ Maternal MUAC (cm) } \\
\hline$<23$ & 131 & 28.4 \\
\hline$\geq 23$ & 331 & 71.6 \\
\hline \multicolumn{3}{|c|}{ History of poor pregnancy outcomes } \\
\hline No & 54 & 11.7 \\
\hline Yes & 408 & 88.3 \\
\hline \multicolumn{3}{|l|}{ Complication during pregnancy } \\
\hline Yes & 83 & 18.0 \\
\hline No & 379 & 82.0 \\
\hline \multicolumn{3}{|c|}{ Type of complication during pregnancy $(n=83)$} \\
\hline $\mathrm{APH}$ & 18 & 21.7 \\
\hline PROM & 12 & 14.5 \\
\hline $\mathrm{PIH}$ & 25 & 30.1 \\
\hline Others $^{\mathrm{b}}$ & 28 & 33.7 \\
\hline
\end{tabular}

${ }^{a}$ Daily laborer, jobless, driver or soldier: ${ }^{b}$ nausea and vomiting, infections, trauma

\section{Obstetrics characteristics}

The majority (91\%) of women had an ANC follow-up. Of those, 20.7, 69.3 and 10\% of women started ANC visit during the first, second and third trimester of pregnancy, respectively (Table 2).

\section{Prevalence of adverse birth outcomes}

The overall prevalence of adverse birth outcomes was 31 . 8\% (95\% CI 27.6\%, 36.1\%). Of those, one-fifth (19.5\%) were low birth weight, while $13.2 \%$ were preterm and $7.8 \%$ stillbirths.

\section{Factors contributing to adverse birth outcomes}

Both bivariable and multivariable logistic regression analyses were done to see the effects of the selected variables on adverse birth outcomes. As it is shown in Table 3, residence, age, mother's education, MUAC, gravidity, ANC visits and complications during pregnancy had significant associations with adverse birth outcomes in the bivariable analysis. However, in the multivariable logistic regression analysis residence, age, MUAC, gravidity, ANC visit

Table 2 Obstetrics characteristics of women delivered in North Wollo zone health institutions, northeast Ethiopia, $2017(n=462)$

\begin{tabular}{lcc}
\hline Variables & Frequency & Percentage \\
\hline ANC follow up & & \\
Yes & 420 & 90.9 \\
No & 42 & 9.1 \\
Frequency of ANC follow up $(\mathrm{n}=420)$ & \\
$\quad<4$ times & 168 & 40.0 \\
4 times & 189 & 45.0 \\
$>4$ times & 63 & 15.0 \\
First ANC visit ( $=420)$ & & \\
First trimester & 87 & 20.7 \\
Second trimester & 291 & 69.3 \\
Third trimester & 42 & 10.0 \\
Iron/folic acid intake & & \\
Yes & 389 & 84.2 \\
No & 73 & 15.8 \\
Maternal gravidity & & 39.8 \\
Primigravida & 184 & 60.2 \\
Multigravida & 278 & 95.7 \\
Labor status & & 4.3 \\
Spontaneous & 442 & \\
Induced & 20 & \\
\hline
\end{tabular}


Table 3 Bivariable and multivariable analyses of adverse birth outcomes of women delivered in North Wollo zone health institutions, northeast Ethiopia, 2017

\begin{tabular}{|c|c|c|c|c|}
\hline \multirow[t]{2}{*}{ Variables } & \multicolumn{2}{|c|}{$\begin{array}{l}\text { Adverse } \\
\text { birth } \\
\text { outcomes } \\
\end{array}$} & \multirow[t]{2}{*}{ COR (95\%) } & \multirow[t]{2}{*}{ AOR (95\%) } \\
\hline & Yes & No & & \\
\hline \multicolumn{5}{|l|}{ Residence } \\
\hline Urban & 75 & 211 & 1.0 & 1.0 \\
\hline Rural & 72 & 104 & $2.0(1.31-2.91)$ & $1.8(1.13,2.78)^{*}$ \\
\hline \multicolumn{5}{|l|}{ Age (years) } \\
\hline$<20$ & 8 & 31 & $0.6(0.27-1.34)$ & $0.5(0.20,1.20)$ \\
\hline $20-34$ & 107 & 248 & 1.00 & 1.00 \\
\hline$\geq 34$ & 32 & 36 & $2.1(1.22-3.49)$ & $2.2(1.21,4.05)^{*}$ \\
\hline \multicolumn{5}{|l|}{ Mother's education } \\
\hline Unable to write and read & 50 & 72 & $2.6(1.43,4.77)$ & $1.8(0.90,3.40)$ \\
\hline Able to write and read & 31 & 50 & $2.3(1.20,4.50)$ & $1.4(0.65,2.83)$ \\
\hline Primary school & 23 & 64 & $1.4(0.69,2.66)$ & $1.6(0.79,3.42)$ \\
\hline Secondary school & 22 & 50 & $1.7(0.83,3.32)$ & $2.0(0.92,4.94)$ \\
\hline College and above & 21 & 79 & 1.0 & 1.0 \\
\hline \multicolumn{5}{|l|}{ Maternal MUAC } \\
\hline$<23$ & 59 & 72 & $2.3(1.48,3.45)$ & $3.1(1.90,4.94)^{*}$ \\
\hline$\geq 23$ & 88 & 243 & 1.00 & 1.00 \\
\hline \multicolumn{5}{|l|}{ Gravidity } \\
\hline Primigravida & 44 & 140 & 1.0 & 1.0 \\
\hline Multigravida & 103 & 175 & $1.9(1.23-2.84)$ & $1.8(1.08,3.06)^{*}$ \\
\hline \multicolumn{5}{|l|}{ ANC visit } \\
\hline Yes & 126 & 294 & 1.0 & 1.0 \\
\hline No & 21 & 21 & $2.3(1.23,4.42)$ & $2.1(1.02,4.40)^{*}$ \\
\hline \multicolumn{5}{|c|}{ Complication during pregnancy } \\
\hline Yes & 39 & 44 & $2.2(1.37,3.61)$ & $2.1(1.23,3.55)^{*}$ \\
\hline No & 108 & 271 & 1.0 & 1.0 \\
\hline
\end{tabular}

*Significantly associated factors at a p-value $<0.05$

and complications during pregnancy were significantly and independently associated with adverse birth outcomes. Accordingly, the odds of having adverse birth outcomes increased by $80 \%(\mathrm{AOR}=1.8 ; 95 \%$ CI $1.13,2.78$ ) among women who lived in a rural area as compared with women who lived in an urban area. The likelihood of encountering adverse birth outcomes was 2.2 times $(\mathrm{AOR}=2.2 ; 95 \%$ CI $1.21,4.05)$ higher among women aged $\geq 34$ years compared to women aged $20-34$ years. Moreover, the odds of developing adverse birth outcomes among women whose MUAC was less than $23 \mathrm{~cm}$ were 3 times $(\mathrm{AOR}=3.1 ; 95 \% \mathrm{CI} 1.90,4.94)$ higher compared to women whose MUAC was $\geq 23 \mathrm{~cm}$.

In this study, the higher odds of developing adverse birth outcomes were also observed among multigravida $(\mathrm{AOR}=1.8 ; 95 \% \mathrm{CI} 1.08,3.06)$ than primigravida women. Likewise, the odds of exhibited adverse birth outcomes among women with complications during pregnancy were 3 times $(\mathrm{AOR}=3.1,95 \% \mathrm{CI} 1.90,4.94)$ higher compared to those of their counterparts (Table 3).

\section{Discussion}

This study was conducted to assess the prevalence and factors associated with adverse birth outcomes among women who delivered in North Wollo zone health institutions, northeast Ethiopia. The overall prevalence of adverse birth outcomes was found to be $31.8 \%$ (95\% CI $27.6 \%, 36.1 \%)$. This finding is higher than those of studies conducted in Gondar (23\%) [18], Hosanna Town (24.5\%) [19], Suhul Hospital, Tigray (22.6\%) [17], Tanzania (18\%) [22], and China (23.5\%) [23]. The possible reason for the difference might be variations in the areas of studies. For instance, the studies in Gondar, Hosanna and Suhul hospitals were hospital-based unlike this study which was also conducted at health centers. Commonly, health centers are located in a rural area to provide services to rural women who are usually unemployed, overworked and have poor access to antenatal care, labor, and delivery services. Furthermore, methodological [24] and socioeconomic $[24,25]$ variations may explain the differences in adverse birth outcomes in Ethiopia on one hand and Tanzania, Ghana and China on the other hand.

Women who live in rural areas are unemployed and less informed about pregnancy, labor and delivery. Moreover, cultural or traditional taboos have a great effect on the nutritional status of women through the prohibition of essential foods and or drinks, are commonly practiced in rural areas, such women are more likely to develop adverse birth outcomes than urban dwellers. Our finding is similar to those of studies reported in Gamo Gofa [26], China [23] and Hosana town [19].

In this study, women $\geq 34$ years of age were at higher risk of encountering adverse birth outcomes. This is supported by other findings in China [23]. Perhaps because of the advanced maternal age result in adverse pregnancy outcomes [27, 28].

Women with a Mid Upper Arm Circumference (MUAC) less $23 \mathrm{~cm}$ were three times more likely to have adverse birth outcomes than women with MUAC $\geq 23 \mathrm{~cm}$. This result is in agreement with those of other studies in Dessie [29]. That is because MUAC less than $23 \mathrm{~cm}$ might be related to maternal undernutrition which affects the fetus in the womb. Poor nutrition during child and adulthood might persist in the offspring, too.

Multigravida women were twice as likely to develop adverse birth outcomes than primigravida women. This finding is supported by other studies in Tigray [17] and Gamo Gofa [26]. This might be due to the socioeconomic burden which increases the sharing of food among family members. 
Women who did not attend ANC were more likely to have adverse birth outcomes when compared to those who used the service. This finding is in line with those of studies in Dessie [29], Gondar [18] and Tanzania [22]. This might be because attending antenatal care helps women to have an awareness of the danger signs during pregnancy, delivery and postnatal period. It also improves health-seeking behavior, orients women on potential complications, birth readiness and help them to identify pregnancy-related problems.

Unrecognized and untreated pregnancy-related health problems put women and their fetus at risk of many problems. In this study, women with complications during pregnancy were more likely to have adverse birth outcomes. Again, this study is consistent with other studies in Dessie [29] and Hosanna town [19].

\section{Conclusion}

This study revealed that the prevalence of the adverse birth outcomes in North Wollo zone was 31.8\%. Residence, age, gravidity, Mid Upper Arm Circumference (MUAC), antenatal care (ANC) and pregnancy complications were mainly associated with adverse birth outcomes. Therefore, increasing the accessibility of health institutions, developing strategies and policies to prevent, diagnose and treat complications before and during pregnancy are recommended. Creating and raising awareness of women on the effect of pregnancy at an advanced age, and providing timely and focused antenatal care (ANC) follow up to all pregnant women are very important to minimize the problem.

\section{Limitations of the study}

Being a cross-sectional study design attempt to our work did not establish the possible temporal relationship between dependent and independent variables. Besides, recall bias in finding out the gestational age of pregnant women was not ruled out.

\section{Abbreviations \\ ANC: antenatal care; $\mathrm{Cl}$ : confidence interval; IQR: inter quartile range; MUAC : mid upper arm circumference; PIH: pregnancy induced hypertension; $\mathrm{PPH}$ : post-partum hemorrhage; PROM: premature rapture of membrane; SPSS: Statistical Package for Social Sciences.}

\section{Acknowledgements}

The authors have special gratitude for all the study participants for their valuable information. We would like also to thank Woldia University for material support. Finally, the authors appreciation for data collectors for their valuable contribution in data collection activities.

\section{Authors' contributions}

EAK developed the idea of the study, acquired the research proposal, carried out statistical analysis and draft the manuscript. EAK, HDM and MAG facilitated data collection, participated in the design of the study, statistical analyses and critically reviewed the manuscript. All authors read and approved the final manuscript.

\section{Funding}

This study was funded by Woldia University that was not involved in the design of the study, data collection, analysis and interpretation.

\section{Availability of data and materials}

Due to ethical restrictions and privacy concerns, a dataset is available upon request from the author Eskeziaw Abebe: eskeziaw02@gmail.com.

\section{Ethics approval and consent to participate}

Ethical approval was obtained from the Faculty of Health Sciences, Woldia University. Data was collected after getting written informed consent from women whose ages were 18 years and above. A written informed consent was taken from legal guardians for those study participants who were less than 18 years of age. Additionally, assent was secured from participants aged below 18 years. Participants' names or other personal identifications were not written on the questionnaire during data collection.

\section{Consent for publication \\ Not applicable.}

\section{Competing interests}

The authors declare that they have no competing interests.

\section{Author details}

${ }^{1}$ Department of Midwifery, Faculty of Health Sciences, Woldia University, Woldia, Ethiopia. ${ }^{2}$ Department of Statistics, Faculty of Natural and Computational Sciences, Woldia University, Woldia, Ethiopia. ${ }^{3}$ Department of Nursing, Faculty of Health Sciences, Woldia University, Woldia, Ethiopia.

Received: 6 February 2019 Accepted: 13 June 2019

Published online: 24 June 2019

\section{References}

1. Lawn JE, Lee AC, Kinney M, Sibley L, Carlo WA, Paul VK, et al. Two million intrapartum-related stillbirths and neonatal deaths: where, why, and what can be done? Int J Gynecol Obstet. 2009;107:S5-19.

2. Hornstra G, Uauy R, Yang X. The impact of maternal nutrition on the offspring. Basel: Karger Medical and Scientific Publishers; 2005.

3. Kramer MS. The epidemiology of adverse pregnancy outcomes: an overview. J Nutr. 2003;133(5):1592S-6S.

4. Lee AC, Katz J, Blencowe H, Cousens S, Kozuki N, Vogel JP, et al. National and regional estimates of term and preterm babies born small for gestational age in 138 low-income and middle-income countries in 2010. Lancet Glob Health. 2013;1(1):e26-36.

5. Physician for Social Responsibility (PSR). Adverse birth outcomes and environmental health threats: 2009.

6. Gladstone M, Oliver C, Van den Broek N. Survival, morbidity, growth and developmental delay for babies born preterm in low and middle income countries - a systematic review of outcomes measured. PLOS ONE. 2015;10(3):e0120566.

7. World Health Organization (WHO). Born too soon: the global action report on preterm birth. Geneva: World Health Organization; 2012.

8. Petrou S. The economic consequences of preterm birth during the first 10 years of life. BJOG. 2005;112(1):10-5.

9. Ethiopia profile of preterm and low birth weight prevention and care. http://www.everypreemie.org/wpcontent/uploads/2015/11/Ethiopia [press release]. American college of nurse-midwives, 2015.

10. Negrato CA, Gomes MB. Low birth weight: causes and consequences. Diabetol Metabol Syndr. 2013:5(1):49.

11. Wardlaw T, Blanc A, Zupan J, Åhman E. Low birth weight: country, regional and global estimates. New York: United Nations Children's Fund and World Health Organization; 2004.

12. Department of Health and Human Services. Health resources and services administration, Maternal and Child Health Bureau. USA: Child Health; 2011. 
13. Central Statistical Agency (CSA) [Ethiopia], ICF. Ethiopia Demographic and Health Survey 2016. Addis Ababa, Ethiopia, and Rockville, Maryland, USA: CSA and ICF; 2016.

14. Frøen F, Lawn JE, Heazell AEP, Flenady V, de Bernis L, Kinney MV. Ending preventable stillbirths, http://www.thelancet.com/pb/assets/raw/Lancet/ stories/series/stillbirths2016-exec-summ.pdf. 2016.

15. Lawn JE, Blencowe H, Waiswa P, Amouzou A, Mathers C, Hogan D, et al. Stillbirths: rates, risk factors, and acceleration towards 2030. Lancet. 2016;387(10018):587-603.

16. Banteyerga $\mathrm{H}$. Ethiopia's health extension program: improving health through community involvement. 2011

17. Adhena T, Haftu A, Gebre G, Dimtsu B. Assessment of magnitude and associated factors of adverse birth outcomes among deliveries at Suhul Hospital Shire Tigray, Ethiopia from September, 2015 to February, 2016. Res Rev J Med Sci Technol. 2017;6(1):1-10.

18. Adane AA, Ayele TA, Ararsa LG, Bitew BD, Zeleke BM. Adverse birth outcomes among deliveries at Gondar University Hospital, Northwest Ethiopia. BMC Pregnancy Childbirth. 2014;14:90.

19. Abdo RA, Endalemaw TB, Tesso FY. Prevalence and associated factors of adverse birth outcomes among women attended maternity ward at Negest Elene Mohammed Memorial General Hospital in Hosanna Town, SNNPR, Ethiopia. J Women's Health Care. 2016;5:324.

20. Adane AA, Ayele TA, Ararsa LG, Bitew BD, Zeleke BM. Adverse birth outcomes among deliveries at Gondar University Hospital, Northwest Ethiopia. BMC Pregnancy Childbirth. 2013;14:90.

21. World Health Organization (WHO). International statistical classification of diseases and related health problems. Geneva: World Health Organization; 2004.

22. Watson-Jones D, Weiss HA, Changalucha JM, Gumodoka B, Todd J, Bulmer J, Balira R, et al. Adverse birth outcomes in United Republic of
Tanzania_impact and prevention of maternal risk factors. Bull World Health Organ. 2007:85:9-18

23. Lin L, Wei Y, Zhu W, Wang C, Su R, Feng H, et al. Prevalence, risk factors and associated adverse pregnancy outcomes of anaemia in Chinese pregnant women: a multicentre retrospective study. BMC Pregnancy Childbirth. 2018;18(1):111.

24. Blumenshine PES, Barclay CJ, Cubbin C, Braveman PA. Socioeconomic disparities in adverse birth outcomes: a systematic review. Am J Prev Med. 2010;39(3):263-72.

25. Campbell E, Seabrook JA. The influence of socio-economic status on adverse birth outcomes. Can J Midwifery Res Pract. 2016;15(2):11-20.

26. Gebremeskel F, Gultie T, Kejela G, Hailu D, Workneh Y. Determinants of adverse birth outcome among mothers who gave birth at hospitals in Gamo Gofa Zone, Southern Ethiopia: a facility based case control study. Qual Prim Care. 2017;25(5):259-66.

27. Kenny LC, Lavender T, McNamee R, O'Neill SM, Mills T, Khashan AS. Advanced maternal age and adverse pregnancy outcome: evidence from a large contemporary cohort. PLoS ONE. 2013;8(2):e56583.

28. Balayla A, Azoulay L, Assayag J, Benjamin A, Abenhaim HA. Effect of maternal age on the risk of stillbirth: a population-based cohort study on 37 million births in the United States. Am J Perinatol. 2011;28(08):643-50.

29. Cherie N, Mebratu A. Adverse birth out comes and associated factors among delivered mothers in Dessie Referral Hospital, North East Ethiopia. J Women's Health Reprod Med. 2017;1(1):4.

\section{Publisher's Note}

Springer Nature remains neutral with regard to jurisdictional claims in published maps and institutional affiliations.
Ready to submit your research? Choose BMC and benefit from:

- fast, convenient online submission

- thorough peer review by experienced researchers in your field

- rapid publication on acceptance

- support for research data, including large and complex data types

- gold Open Access which fosters wider collaboration and increased citations

- maximum visibility for your research: over 100M website views per year

At BMC, research is always in progress.

Learn more biomedcentral.com/submissions 